\title{
Immunological and morphological analysis of heterotopic ossification differs to healthy controls
}

\author{
Klemens Trieb ${ }^{*}$, Andreas Meryk², Sascha Senck ${ }^{3}$, Erin Naismith and Beatrix Grubeck-Loebenstein ${ }^{2}$
}

\begin{abstract}
Background: Formation of lamellar bone in non-osseus tissue is a pathological process called heterotopic ossification. It is the aim of this study to analyse the morphology and immunological status of patients with heterotopic ossification compared to individual healthy persons.

Methods: Human bone marrow and blood samples were obtained from 6 systemically healthy individuals and 4 patients during resection of heterotopic ossification from bone at hip arthroplasty. Bone was fragmented and treated with purified collagenase. Immunofluorescence surface staining was performed and analyzed with flow cytometry. Microcomputed tomography scanning was done performed at a resolution of 11 and $35 \mu \mathrm{m}$ isometric voxel size respectively using a two different cone beam X-computer tomography systems and a microfocus X-ray tube. Subsequently the volume data was morphometrically analysed.
\end{abstract}

Results: The monocytes, stem cells, stroma cells and granulocytes progenitor cells were strongly reduced in the heterotopic ossification patient. Additionally a significant reduction of stromal stem cells cells and CD34 positive stem cells was observed. The frequency of NK-cells, B cells and T cells were not altered in the patients with heterotopic ossification compared to a healthy person. Micromorphometric parameters showed a lower content of mineralized bone tissue compared to normal bone. Mean trabecular thickness showed a high standard deviation, indicating a high variation in trabecular thickness, anisotropy and reducing bone strength.

Conclusions: This work shows altered immunological distribution that is accompanied by a low decrease in bone volume fraction and tissue mineral density in the heterotopic ossification sample compared to normal bone. Compared to healthy subjects, this might reflect an immunological participation in the development of this entity.

\section{Background}

Formation of lamellar bone in non-osseus tissue is a pathological process called heterotopic ossification $(\mathrm{HO})$. This can occur in muscle or connective tissue as a result of trauma, surgery, fractures, neurological injury or genetic mutations (fibrodysplasia ossificans progressiva, Albright's hereditary osteodystrophy). It causes major clinical burdens due to limitation of motion, persistent pain and nerve entrapement [1-4]. So far morphometric data on morphometric indices like porosity, tissue mineral density, and trabecular volume is fragmentary for human samples and immunological data are rarely available. Skeletal muscle

\footnotetext{
* Correspondence: klemens.trieb@klinikum-wegr.at

${ }^{1}$ Department of Orthopaedics, Klinikum Wels-Grieskirchen, Grieskirchnerstr 42, 4600 Wels, Austria

Full list of author information is available at the end of the article
}

tissue has a wide capacity for regenaration by myogenic stem cells in combination with mesenchymal stromal cells. It is not clear which factors induce enchondral bone formation during this process. Some studies have proposed endothelial or brown adipogenic cells as a or the source for $\mathrm{HO}$. The reciprocal interactions between bone and the immune system have become more the subject of increased attention in recent years and the so called osteoimmunology describes cytokine induces bone resorption and inflammatory induced ossification [5-14].

Neurogenic HO induced by spinal cord or traumatic brain injury is described but detailed characteristion of immunologigal and morphologic changes are hardly available. It is the aim of this study to analyse the morphology and immunological status of patients with heterotopic ossification compared to individual healthy persons [15]. 


\section{Methods}

\section{Patients}

\section{Human sample collection and preparation}

Heterotopic ossification tissue was obtained at resection from four patients and divided for further analysis. The first was obtained from male in the beginning $50 \mathrm{~s}$ patient who suffered a central ganglion bleeding one year before and developed a central nervous system induced $\mathrm{HO}$ in the left musculus vastus. The second was obtained from man in the end 60s suffering from a postdicectomy ischiadical lesion developing peripheral neuroathy induced $\mathrm{HO}$ after hip arthroplsaty. The third was obtained from woman in the beginning 20s developing $\mathrm{HO}$ after fixation of a femoral neck fracture without neurological impairment. The fourth healthy patient underwent hip replacement (male mid 50s) after an old femur fracture with a removed intramedullary nail. In the gluteus he had a HTO which had to be removed for hip approach, so we gained normal bone (femoral head) and HTO from one patient for analysis. Human bone marrow (BM) samples were obtained from age matched systemically healthy individuals (4 male, 2 female, mean age 52 years) who did not receive immunomodulatory drugs or suffer from diseases known to influence the immune system, including autoimmune diseases and cancer. Informed consent for test and publication was given and documented from each patient after the study received approval of the local institution of the corresponding author and none of the authors has competing interests according to BioMed Central's guidance. Total hip arthroplasty was performed by an antero-lateral minimal invasive approach and bone was harvested from the resected neck and femoral head to isolate bone marrow mononuclear cells (BMMCs) [16]. Bone fragments were washed once with complete RPMI medium (RPMI 1640 supplemented with $10 \%$ FCS, $100 \mathrm{U} / \mathrm{ml}$ penicillin, and $100 \mu \mathrm{g} / \mathrm{ml}$ streptomycin; Invitrogen) and treated with purified collagenase (CLSPA, Worthington Biochemical; $20 \mathrm{U} / \mathrm{ml}$ in complete RPMI medium) for $1 \mathrm{~h}$ at $37{ }^{\circ} \mathrm{C}$. After centrifugation purification of BMMCs was done by density gradient centrifugation (Ficoll-Hypaque). This methods are described in detail in previous studies [17].

\section{Flow cytometry}

Immunofluorescence surface staining was performed by adding a panel of directly conjugated antibodies to freshly prepared BMMCs. Labelled cells were measured by a FACSCanto II (BD Biosciences) and analyzed with Flowjo.

\section{Microcomputed tomography}

During the scanning procedure, fresh samples were stored in air-sealed polymer sample holders to prevent dehydration. The complete samples were scanned at a resolution of $35 \mu \mathrm{m}$ isometric voxel size using a RayScan 250E cone beam XCT device equipped with a Perkin Elmer flat panel detector $(2048 \times 2048$ pixels with a pixel size $200 \mu \mathrm{m})$ and a Viscom $225 \mathrm{kV}$ microfocus X-ray tube. The X-ray scanning parameters were set to $120 \mathrm{kV}$ and $420 \mu \mathrm{A}$ with an integration time of $1500 \mathrm{~ms}$; a $0.5 \mathrm{~mm}$ thick copper filter-plate was applied to prevent beam hardening artefacts. Hydroxyapatite rods (HA; $8 \mathrm{~mm}$ diameter, 250 and $750 \mathrm{mg}$ $\mathrm{HA} / \mathrm{cm}^{3}$ ) were scanned in the same sealed specimen holder to calibrate images for 1) tissue mineral density (TMD) of the trabecular bone to quantifiy trabecula mineralization and 2) bone mineral density (BMD) of trabecular bone in conjunction with the surrounding soft tissue.

A second scan was conducted on cut out samples (ca. $12 \mathrm{~mm}$ in diameter) of the respective specimen at resolution of $11 \mu \mathrm{m}$ isometric voxel size using a GE Phoenix Nanotom 180 cone beam XCT device equipped with a panel detector $(2300 \times 2300$ pixels $)$ and a $180 \mathrm{kV}$ nanofocus X-ray tube. The X-ray scanning parameters were set to $80 \mathrm{kV}$ and $230 \mu \mathrm{A}$ with an integration time of $600 \mathrm{~ms}$. Image information for each data set was separated into tissue and background using the "advanced threshold" function using Volume Graphics 2.2. Subsequently, volume data was transferred to CTAn (Version 1.16; Bruker) for morphometric analysis. Calculated morphometric indices include bone volume fraction (BV/TV, bone volume/ total volume), mean trabecular thickness (TbTh.mean), standard deviation of trabecular thickness (TbTh.SD), mean trabecular separation (TbSp.mean), standard deviation of trabecular separation (TbSp.SD), degree of anisotropy (DA), and connectivity (Con). The computation of these indices is implemented in CTAn and is based on the work of Hildebrand and Ruegsegger [18] and Remy and Thiel [19]. Moreover, TMD and BMD were computed using a calibration curve based on the 16-bit grey values of the two above mentioned Hydroxyapatite rods.

\section{Histology}

For histology, formalin-fixed $\mathrm{HO}$ tissue was decalcified and embedded in methyl metacrylate. Sections $(6 \mu \mathrm{m})$ were cut, deplastified and stained with Goldner trichrome for comparative histology.

\section{Statistical analysis}

The data obtained in the study are following a non-parametric distribution. Therefore statistical significance was assessed by Spearman correlation analysis, Mann-Whitney test and Wilcoxon matched pairs test, a $p$-value of less than 0.05 was considered as significant. All data are shown as mean \pm standard error of the mean (SEM). Statistical analysis was performed using GraphPad Prism software version 5.0 (GraphPad Software). To determine the significance of differences between two groups, the unpaired two-tailed t test were used, as indicated in the figure legends. 


\section{Results}

\section{Morphology and histology}

The heterotopic ossification is characterized by an inappropriate activation of mesenchymal stem cells in the skeletal muscle tissue, which leads to an extraskeletal bone-containing bone cells, which are derived from several lines. Figure 1 shows the a.p. radiograph of the left hip showing $\mathrm{HO}$ formation in the musculus vastus limiting hip flexion and inducing permanent pain. Figure 2 depicts the photograph of the $\mathrm{HO}$ after resection and before seperation for different experiments. The histological examination shows the presence of different tissue types, such as mature bones, cartilage and fetal cells. It has been shown that the presence of brown fetal cells reduces the oxygen content and thereby promotes angiogenesis and enchondral ossification, the white fat cells are also present (Fig. 3).

\section{Flow cytometry}

Using flow cytometry, the BMMCs of 6 healthy persons can be separated into two populations based on FSC and SSC. The cell population with a low SSC (SSClow) are mainly lymphocytes, monocytes and stem cells, whereas the cells with a higher SSC (SSChigh) are mainly stroma cells and granulocytes progenitor cells. The SSChigh cell population represents $50-70 \%$ of all BMMCs but were nearly absent in the patient with heterotopic ossification (Table 1). To further investigate the SSClow population of the BMMCs, we stained with specific markers for monocytes, NK-cells, T cells, B cells and stem cells. The frequency of NK-cells, B cells and T cells were not altered in the patient with $\mathrm{HO}$ compared to the healthy controls. However, stromal stem cells and stem cells positive for $\mathrm{CD} 34$ were significantly reduced in the $\mathrm{HO}$ patients (Figs. 4 and 5). Interestingly we have the same results in the fourth patient comparing normal bone and HTO from the same person. Stromal stem cells (45,4 vs.

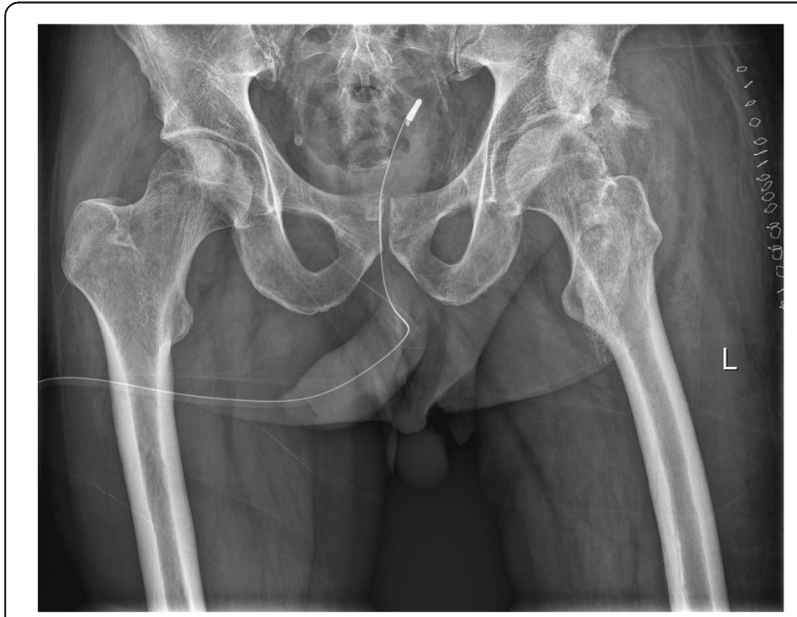

Fig. 1 Radiograph of the HTO of the left hip

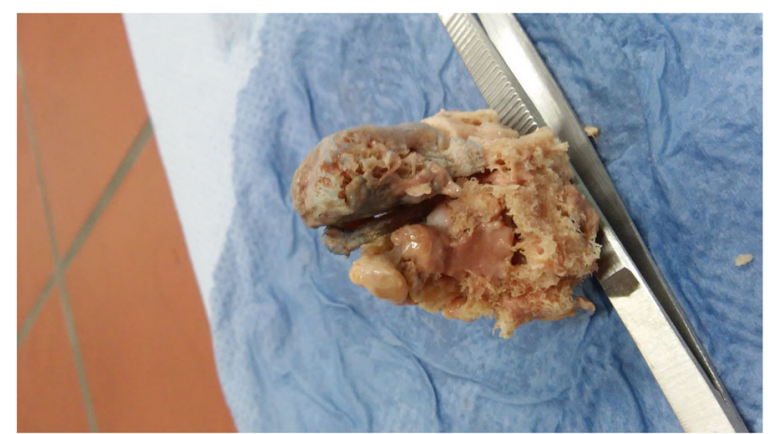

Fig. 2 Photograph of the $\mathrm{HO}$ after resection and before splitting for different experiments

25,9) and stem cells positive for CD34 (3,61 vs. 2,09) were reduced in the $\mathrm{HO}$ bone, too (Table 1, Fig. 6).

\section{Bone morphometric parameters}

Due to the voxel size of $35 \mu \mathrm{m}$ in the scans of the complete samples, only trabeculae of a thickness larger then $105 \mu \mathrm{m}$ are considered in the morphometric analysis since at least three voxels are necessary to ascertain that detail detectability is sufficiently high. To investigate the distribution of trabeculae thinner than $105 \mu \mathrm{m}$ we scanned a cut-out part at a higher resolution at $11 \mu \mathrm{m}$ voxel size. The values of the extracted microstructural parameters are presented in Table 2.

Despite the rather large volume of sample 1 (ca. $\left.24 \mathrm{~cm}^{3}\right)$, bone volume fraction (BV/TV) is relative low (14.5\%), showing a low content of bone tissue compared to normal $36.46 \pm 15.38 \%)$, osteoporotic $(25.03 \pm 6.22 \%)$, and metastatic bone $(24.29 \pm 12.26 \%)$ [28]. The high value of mean trabecular separation (TbSp.mean) and its high standard deviation (TbSp.SD) support this finding. Likewise, mean trabecular thickness (TbTh.mean) shows a high standard deviation, indicating a high variation in trabecular thickness from extra skeletal bone to parts of

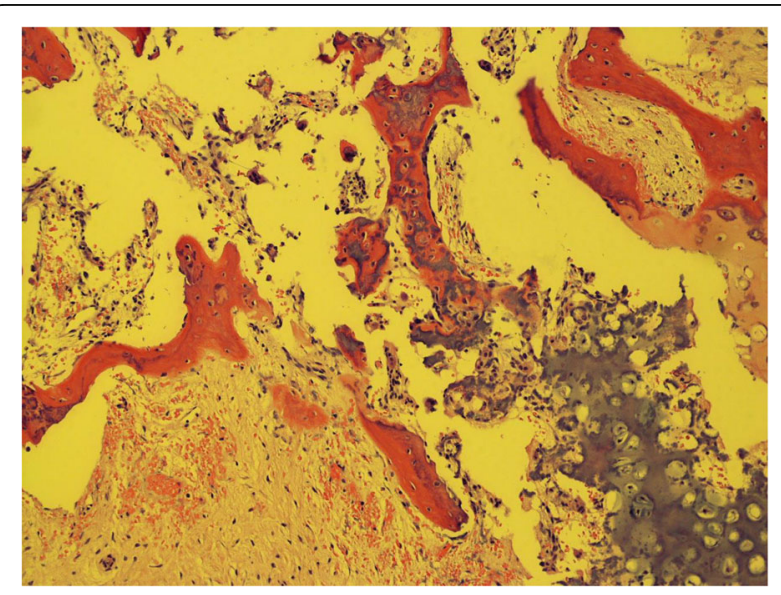

Fig. 3 Histological picture (haematoxilin eosin $\times 100$ ) 
Table 1 Flow cytometry analysis of BMMCs

\begin{tabular}{llllll}
\hline & \multicolumn{2}{l}{ Healthy } & & & HTO \\
\cline { 2 - 3 } & mean & SEM & & mean & SEM \\
\hline T cells & 24,72 & 2.95 & & 24.75 & 4.08 \\
CD4 & 46.35 & 3.16 & & 42.48 & 9.15 \\
CD8 & 44.88 & 3.28 & & 48.73 & 7.26 \\
B cells & 9.357 & 1.22 & & 13.20 & 2.43 \\
SSC high & 39.9 & 3.43 & & $16.77^{* *}$ & 5.64 \\
CD34+ Stem cells & 12.74 & 2.70 & & $1.77^{*}$ & 0.46 \\
Monocytes & 9.57 & 2.26 & & 4.16 & 1.58 \\
NK cells & 4.87 & 0.79 & & 5.92 & 2.95 \\
\hline * $p<0,05 ; * * 0,01$ & & & &
\end{tabular}

the remaining normal bone adjacent to the resection site. While the central region of the sample shows low values of trabecular thickness, regions at the section site and the outer regions encompassing the central part are characterized by bone structures with a higher trabecular thickness (Fig. 7).

Samples 2-4 show higher BV/TV values between 29,69\% and $50,91 \%$ (see Tab. 1), exceeding reported values for bone volume fraction [28]. TbSp.mean and TbSp.SD are less pronounced compared to the complete sample 1, showing values between $237.85 \mu \mathrm{m}$ (Sample 2) and $1097.32 \mu \mathrm{m}$ (Sample 4) for mean trabecular separation. Depending on the microstructure of the investigated subregion, values for TbSp.mean are either increased (Sample 2) or decreased (Sample 1, 3 and 4). This illustrates the high regional variation in the microstructural composition of the respective sample. The same applies to mean trabecular thickness, Sample 2 and 3 showing higher TbTh.mean values

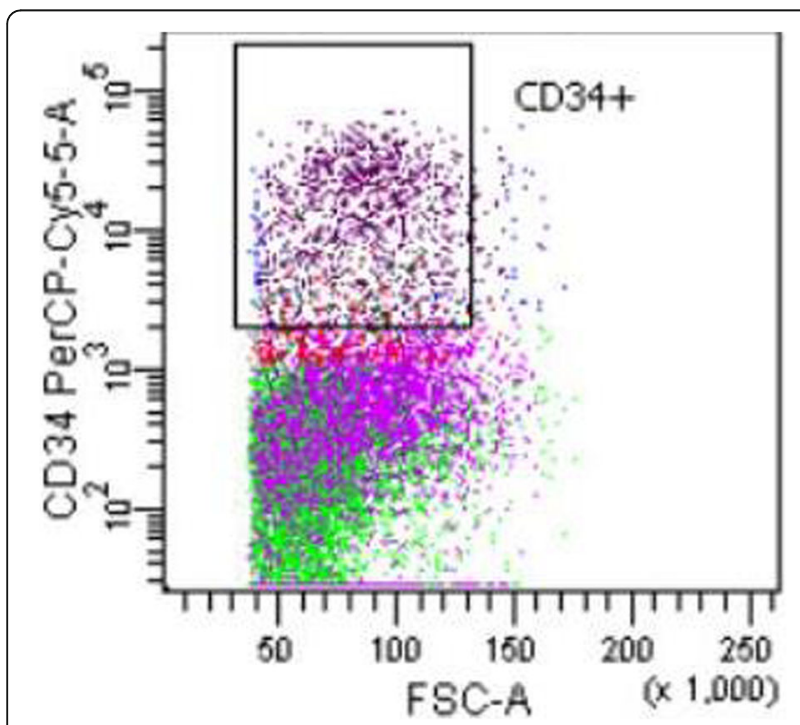

Fig. 4 Subpopulations in BMMCs: after excluding dead cells, SSC cells expressing CD34 were gated

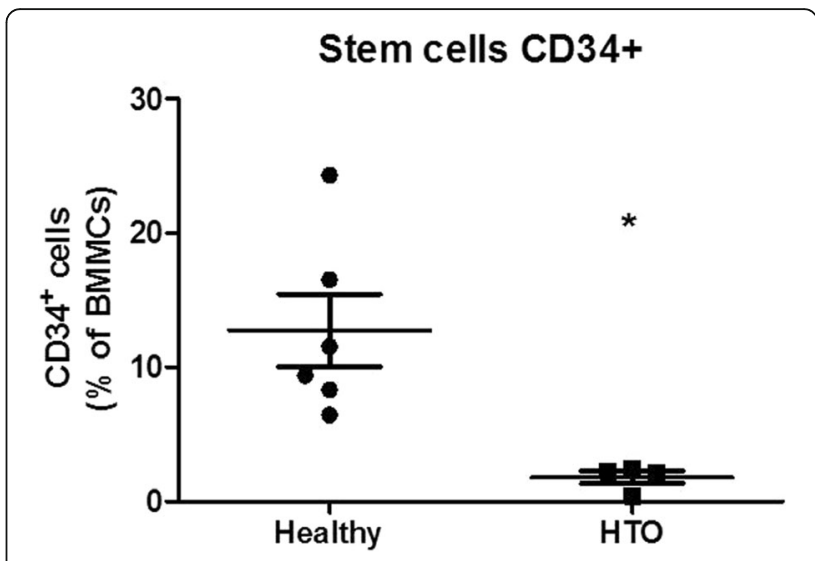

Fig. 5 Flow cytometry of the samples (CD 34+ cells)

compared to Sample 1. In general, the high standard deviation for TbTh.mean (for overview and detail samples) points to a high variation in the regional distribution of thinner and thicker trabeculae in each sample.

Apart from bone volume fraction, degree of anisotropy (DA) of trabecular bone is another important determinant of biomechanical strength. Using the calculation of DA implemented in CTAn, total isotropy is represented by the value 0 and total anisotropy by 1 . In this sample, values between 0.24 and 0.45 point to a rather low low degree of anisotropy, i.e. trabecular alignment along a particular directional axis. However, the low resolution scan of Sample 4 shows a higher DA value. Since, the detail scan of Sample 4 shows a much lower DA value comparable to Samples 1-3, this high value may be explained by very thin trabeculae that are not detected at a lower physical resolution, hence exaggerating the degree of anisotropy. Since thin trabeculae are detected in the detail scan, i.e. those interconnecting larger trabeculae, the total DA is lower. While highly organized bone structures correlate with higher anisotropic values, disordered bone deposition, e.g. of

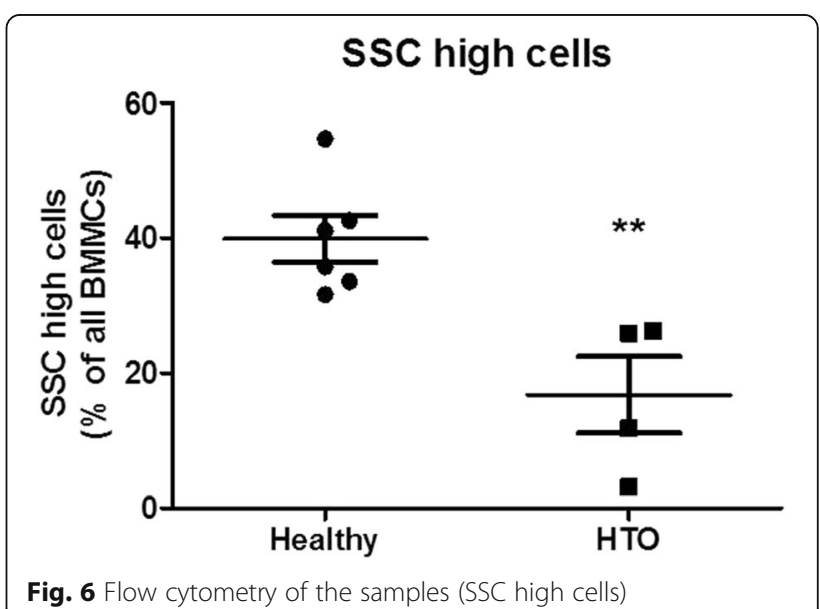


Table 2 Extracted microstructural parameters of the complete sample (35 $\mu \mathrm{m}$ voxel size) and of the cut-out subsample (11 $\mu \mathrm{m}$ voxel size)

\begin{tabular}{|c|c|c|c|c|}
\hline & Sample 1 & Sample 2 & Sample 3 & Sample 4 \\
\hline BV/TV (in \%) & 14,5 & 39,6 & 50,9 & 29,7 \\
\hline TbTh.mean (in $\mu \mathrm{m}$ ) & 312,1 & 446,5 & 352,5 & 280,5 \\
\hline TbTh.SD (in $\mu \mathrm{m}$ ) & 192,2 & 665,5 & 179,7 & 135,5 \\
\hline TbSp.mean (in $\mu \mathrm{m}$ ) & 1634,9 & 237,9 & 467,8 & 1097,3 \\
\hline TbSp.SD (in $\mu \mathrm{m}$ ) & 1391,5 & 350,4 & 312,8 & 863,8 \\
\hline DA & 0,3 & 0,24 & 0,34 & 0,64 \\
\hline TMD (in mg/cm3) & 484,3 & 661,9 & 635,8 & 763,5 \\
\hline BMD (in mg/cm3) & 109,5 & 343,6 & 349,2 & 283,7 \\
\hline
\end{tabular}

reactive woven bone, is associated with decreased anisotropy [29].

In this study we furthermore quantified the degree of mineralization of bone tissue in the $\mathrm{HO}$ sample. Tissue mineral density (TMD) of trabecular bone showed low average values (484.34-763,46 mg HA/ $\mathrm{cm}^{3}$ ) compared to average TMD of normal trabecular bone of the femoral neck, greater trochanter, and proximal tibia (approximately $900 \mathrm{mg} \mathrm{HA} / \mathrm{cm}^{3}$ ) [30]. Also bone mineral density (BMD) of trabecular bone in conjunction with the surrounding soft tissue showed a lower average value in sample $1(109,52 \mathrm{mg}$ $\mathrm{HA} / \mathrm{cm}^{3}$ ) compared to reported normal bone volumetric BMD for women and men without hip fractures $\left(310 \pm 60 \mathrm{mg} / \mathrm{cm}^{3}\right.$ and $310 \pm 60 \mathrm{mg} / \mathrm{cm}^{3}$, respectively) and with hip fractures $(250 \pm 40$ and 260 $\pm 40 \mathrm{mg} / \mathrm{cm}^{3}$, respectively) [31]. Nevertheless, BMD values for Sample 2, 3 and Sample 4 show higher values compared to Sample1.

\section{Discussion}

A neurogenic heterotopic ossification is a serious complication of traumas or disorders of the central nervous system observed in $20 \%$ of patients with this condition [2]. The hip and elbow joints affected predominantly are with severe pain, loss of movement and nerve compression syndromes. In addition, complications of the urinary tract system and pressure ulcers may arise in this disease [1-4]. In addition to conservative therapy with NSAIDs or bisphosphonates, surgical resection is indicated, with local recurrence being described.Neurogenic heterotopic ossification is characterized by ectopic bone formation in the soft tissue and muscle tissue around large joints, especially the hip and elbow joints. The severity of the $\mathrm{HO}$ depends on the severity of the brain damage. In the initial stage, NHO is difficult to diagnose and can also be interpreted as phlebitis, arthritis or cellulitis in a differential diagnosis, which often leads to a treatment delay. It is then necessary to take care of the hygiene in the case of concomitant diseases and complications as well as, for example, pressure ulcers, urinary tract infections or pneumonia [1-5].

As a rule, surgical resection occurs within the first year after the occurrence of the disease, whereby the indication for the operation is indicated on the one hand by the size of the ossification, on the other also by pain and possible compression of nerves or blood vessels.

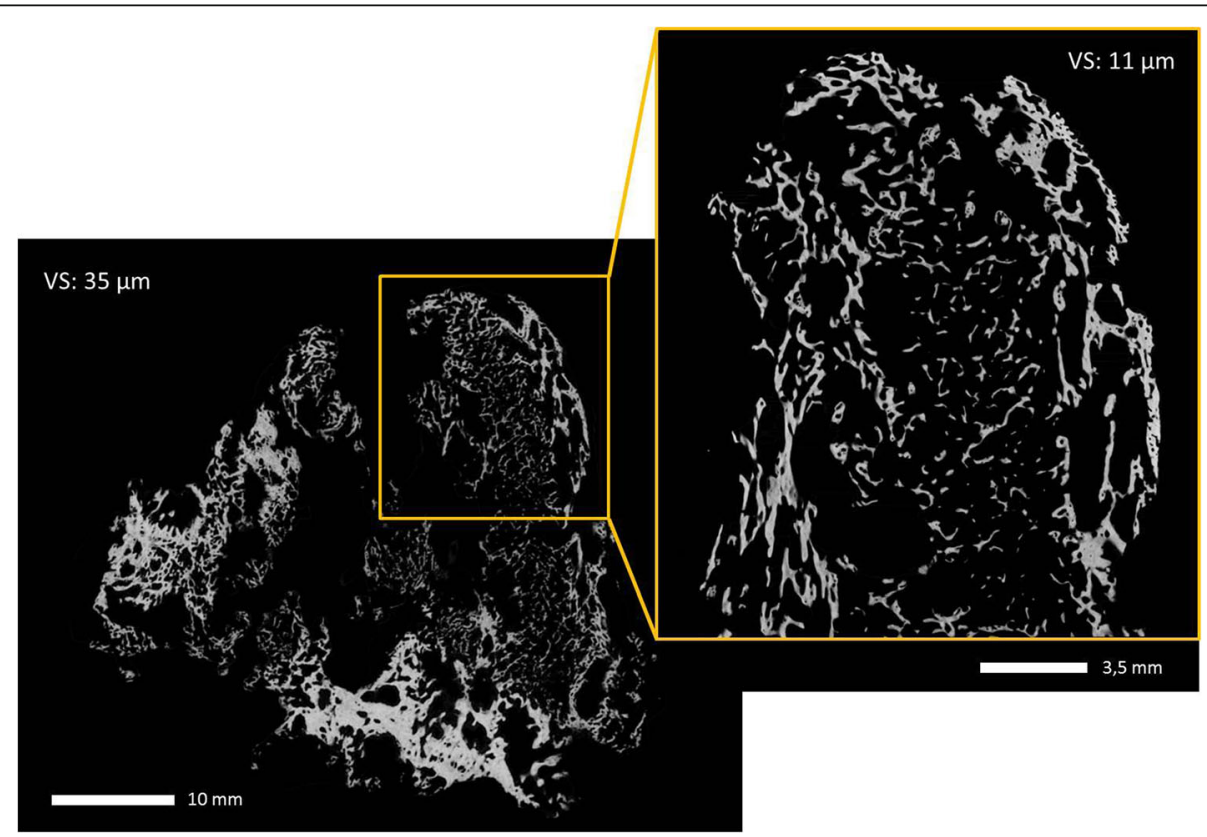

Fig. 7 Microcomputed tomography image of one sample 
Good preoperative planning is important to avoid the potential complications such as infection, fracture, recurrent hemorrhage and nerve injury $[2,20,21]$.

The time should be chosen so that the ossification is mature, but not yet so great that the complication probability becomes more frequent. Setting the right time for resection is not always easy, especially given the recurrence probability determined by the severity of brain damage. Likewise, too late a resection is bad for the adjacent joint, since this it is then stiffened and subsequent mobilization is made more difficult. There are different reports in the literature such as a series with 20 hips and another with 29 patients, with an improvement in the scope of movement in both studies [21,22].

The pathophysiology of the NHO is not fully understood. However, there are 3 causes (traumatic, genetic, neurogenic) that can trigger the formation of the $\mathrm{HO}$ by activating stem cells for proliferation and differentiation [23]. In these patients, humoral factors can be altered; the exact relationship between the nervous system and the bone is not fully understood. It has been shown that some factors such as vasoactive peptides, neurotransmitters and the vasoactive substance can be altered [24-27]. There are some limitations in this study, one is the limited number of patients and another the descriptive concept. But our findings should induce other groups to initiate studies on this topic to get more information on the involvement of the immune system in $\mathrm{HO}$.

In our study it is shown that immunological distribution in heterotopic ossification is altered compared to healthy subjects, this might reflect an immunological participation in the development of this entity. The result is tissue formation with a low bone volume fraction. Morphometric parameters additionally show that the disordered bone deposition in HO, e.g. of reactive woven bone, produces bone tissue that is characterized by a decrease in bone strength due to a low degree of mineralization and anisotropy. Further studies are needed to understand the mechanisms which induce $\mathrm{HO}$.

\section{Conclusions}

This work shows altered immunological distribution that is accompanied by a low decrease in bone volume fraction and tissue mineral density in the heterotopic ossification sample compared to normal bone. Compared to healthy subjects, this might reflect an immunological participation in the development of this entity.

\section{Abbreviations}

BM: Bone marrow; BMD: Bone mineral density; BMMC: Bone marrow mononuclear cells; BV/TV: Bone volume/total volume; Con: Connectivity; DA: Degree of anisotropy; HO: Heterotopic ossification; TbSp.mean: Mean trabecular separation; TbSp.SD: Standard deviation of trabecular separation; TbTh.mean: Mean trabecular thickness; TbTh.SD: Standard deviation of trabecular thickness; TMD: Tissue mineral density
Availability of data and materials

The datasets from this study are available from the corresponding author on reasonable request.

\section{Authors' contributions}

AM, SS, EN carried out the molecular, morphometric studies, immunoassays and histologic studies, participated in the sequence alignment and drafted the manuscript. KT designed the study and drafted the manuscript and BG participated in its coordination. All authors read and approved the final manuscript.

\section{Ethics approval and consent to participate}

Human studies were approved by the Ethics Committee of Innsbruck Medical University (number AN2014-0263 341/4.3), Austria. Written consent for participation was acquired from all patients.

\section{Consent for publication}

not applicable.

\section{Competing interests}

The authors declare that they have no competing interests.

\section{Publisher's Note}

Springer Nature remains neutral with regard to jurisdictional claims in published maps and institutional affiliations.

\section{Author details}

'Department of Orthopaedics, Klinikum Wels-Grieskirchen, Grieskirchnerstr 42, 4600 Wels, Austria. ${ }^{2}$ Institute for Biomedical Aging Research, University of Innsbruck, 5020 Innsbruck, Austria. ${ }^{3}$ Computed Tomography Research Group, University of Applied Sciences Upper Austria, 4600 Wels, Austria.

Received: 6 February 2018 Accepted: 27 August 2018

Published online: 11 September 2018

\section{References}

1. Potter BK, Burns TC, Lacap AP, Granville RR, Gajewski DA. Heterotopic ossification following traumatic and combat-related amputations. Prevalence, risk factors, and preliminary results of excision J Bone Joint Surg Am. 2007:89:476-86.

2. Sullivan MP, Torres SJ, Mehta S, Ahn J. Heterotopic ossification after central nervous system trauma: a current review. Bone Joint Res. 2013;2:51-7.

3. Alfieri KA, Forsberg JA, Potter BK. Blast injuries and heterotopic ossification. Bone and Joint Research. Aug 2012:1:174-9.

4. Simonsen LL, Sonne-Holm S, Krasheninnikoff M, Engberg AW. Symptomatic heterotopic ossification after very severe traumatic brain injury in 114 patients: incidence and risk factors. Injury. 2007;38:1146-50.

5. Downey J, Lauzier D, Kloen P, Klarskov K, Richter M, Hamdy R, Faucheux N, Scimè A, Balg F, Grenier G. Prospective heterotopic ossification progenitors in adult human skeletal muscle. Bone. 2015;71:164-70.

6. Wittenberg RH, Peschke $U$, Bötel U. Heterotopic ossification after spinal cord injury: epidemiology and risk factors. J Bone Joint Surg (Br). 1992;74-B:215-8.

7. van Kuijk AA, Geurts AC, van Kuppevelt HJ. Neurogenic heterotopic ossification in spinal cord injury. Spinal Cord. 2002;40:313-26.

8. Ramirez D, Ramirez M, Reginato A, Medici M. Molecular and cellular mechanisms of heterotopic ossification. Histol Histopathol. 2014;29:1281-5.

9. Convente $\mathrm{M}$, Wang H, Pignolo R, Kapaln F, Shore E. The immunological contribution to heterotopic ossification disorders. Curr Osteoporosis Rep. 2015:13:116-24

10. Brownley RC, Agarwal S, Loder S, Eboda O, Li J, Peterson J, et al. Characterization of heterotopic ossification using radiographic imaging: evidence for a paradigm shift. PLoS One. 2015;10:e0141432. https://doi.org/10.1371/journal.pone.0141432.

11. Ji Y, Christopherson GT, Kluk MW, Amrani O, Jackson WM, Nesti LJ. Heterotopic ossification following musculoskeletal trauma: modeling stem and progenitor cells in their microenvironment. Adv Exp Med Biol. 2011;720:39-50.

12. Leblanc E, Trensz F, Haroun S, Drouin G, Bergeron E, Penton CM. BMP-9induced muscle heterotopic ossification requires changes to the skeletal muscle microenvironment. Bone Miner Res. 2011;26:1166-77.

13. Kan L, Kessler JA. Evaluation of the cellular origins of heterotopic ossification. Orthopedics. 2014;37:329-40. 
14. Medici D, Shore EM, Lounev VY, Kaplan FS, Kalluri R, Olsen BR. Conversion of vascular endothelial cells into multipotent stem-like cells. Nat Med. 2010;16: 1400-6.

15. Kan C, Kann L. The burning questions of heterotopic ossification. Ann Transl Med 215. 3:14-6.

16. Stadler N, Lehner J, Trieb K. Prospective mid-term results of a consecutive series of a short stem. Acta Orthop Belg. 2016;82:372-5.

17. Pangrazzi L, Meryk A, Naismith E, Koziel R, Lair J, Krismer M, Trieb K, Grubeck-Loebenstein B. "Inflamm-aging" influences immune cell survival factors in human bone marrow. Eur J Immunol. 2016; https://doi.org/10. 1002/eji.201646570.

18. Hildebrand T, Ruegsegger P. A new method for the model independent assessment of thickness in three dimensional images. J Microsc. 1997;185:67-75.

19. Remy $E$, Thiel E. Medial axis for chamfer distances: computing look-up tables and neighbourhoods in 2D or 3D. Pattern Recogn Lett. 2002;23:649-61.

20. Meiners T, Abel R, Bohm V, Gerner HJ. Resection of heterotopic ossification of the hip in spinal cord injured patients. Spinal Cord. 1997;35:443-5.

21. Garland DE, Orwin JF. Resection of heterotopic ossification in patients with spinal cord injuries. Clin Orthop Relat Res. 1989;(242):169-76.

22. Moore TJ. Functional outcome following surgical excision of heterotopic ossification in patients with traumatic brain injury. J Orthop Trauma. 1993;7:11-4.

23. Kurer MH, Khoker MA, Dandona P. Human osteoblast stimulation by sera from paraplegic patients with heterotopic ossification. Paraplegisa. 1992;30:165-8

24. Bidner SM, Rubins IM, Desjardins JV, Zukor DJ, Goltzman D. Evidence for a humoral mechanism for enhanced osteogenesis after head injury. J Bone Joint Surg Am. 1990;72:1144-9.

25. Hohmann E, Elde R, Rysavy J, Einzig S, Gebhard R. Innervation of peristoneum and bone by symphatetic vasoactive intestinal peptidecontaining nerve fibers. Science. 1986;232:868-71.

26. Wang $L$, Tang $X$, Zhang $H$, et al. Elevated leptin expressionin rat model of traumatic spinal cord injury and femoral fracture. J Spinal Cord Med. 2011:34:501-9.

27. Forsberg J, Potter B, Safford S, Do E. Inflammatory Markers Portend heterotopic ossification and wound failure in combat wounds? Clin Orthop Relat Res. 2014;472:2845-54.

28. Nazarian A, von Stechow D, Zurakowski D, Müller R, Snyder BD. Bone volume fraction explains the variation in strength and stiffness of cancellous bone affected by metastatic cancer and osteoporosis. Calcif Tissue Int. 2008; 83:368-79

29. Cole HA, Ohba T, Ichikawa J, Nyman JS, Cates JMM, Haro H, et al. Microcomputed tomography derived anisotropy detects tumor provoked deviations in bone in an orthotopic osteosarcoma murine model. PLoS One. 2014;9:1-7.

30. Wang J, Kazakia GJ, Zhou B, Shi XT, Guo XE. Distinct tissue mineral density in plate and rod-like trabeculae of human trabecular bone. J Bone Min Res. 2015;30:1641-50

31. Center JR, Nguyen TV, Pocock NA, Eisman JA. Volumetric bone density at the femoral neck as a common measure of hip fracture risk for men and women. JCEM. 2004;89:2776-82.

Ready to submit your research? Choose BMC and benefit from:

- fast, convenient online submission

- thorough peer review by experienced researchers in your field

- rapid publication on acceptance

- support for research data, including large and complex data types

- gold Open Access which fosters wider collaboration and increased citations

- maximum visibility for your research: over $100 \mathrm{M}$ website views per year

At $\mathrm{BMC}$, research is always in progress.

Learn more biomedcentral.com/submissions 